кандидат педагогических наук, доцент, заведующий кафедрой библиографии (Бакинский государственный университет, Азербайджан) m.mehmanali@gmail.com

\title{
ПРОБЛЕМЫ ДЕТСКОГО ЧТЕНИЯ В ИСТОРИИ АЗЕРБАЙДЖАНСКОЙ ПЕДАГОГИЧЕСКОЙ МЫСЛИ
}

В данной статье излагаются проблемы детского чтения в истории педагогической мысли Азербайджана. В частности, изложены позиции Низами Гянджеви, Мирза Кязымбека, А. А. Бакиханова, Мирза Шафи Вазеха, Мирзы Фатали Ахундова, Сеида Азима Ширвани, Фиридун Бека Кочарли, Рашид Бека Эфендиева, Наримана Нариманова, Омара Фаика Неманзаде. Сделаны выводы о значимости научно-педагогической и публицистической деятельности каждого из указанных мыслителей, приведены наиболее ценные с точки зрения исследуемой тематики мысли о роли языка и литературы в обучении детей в школе. Показано значение указанных идей и исследований в современном педагогическом прочессе.

Ключевые слова: история педагогической мысли Азербайджана, детское чтение, икольное обучение, язык и литература, дидактика и методика.

Постановка проблемы. Вопросы детского чтения всегда представляли интерес для исследователейпедагогов, в том числе и в Азербайджане. Азербайджанские мыслители еще с незапамятных времен, когда появилась письменность, придавали большое значение чтению. Еще в XII веке великий мыслительпоэт Азербайджана Низами дал высокую оценку умственному развитию человека, призывая всех, независимо от возраста, стремиться к знаниям, учить науки. Он подчеркивал, что нет предела знаниям. Они постоянно совершенствуют человека. А учить необходимо уже с раннего возраста.

Анализ последних достижений в данной области. Вопросы педагогических идей в творчестве Низами рассматривались многими азербайджанскими исследователями. К примеру, есть монография Б. Апоева [1], статьи и книги С. Н. Микаилова, С. М. Гулиева, Р. Алиева, Т. Т. Бабаевой, А. А. Халафова, Э. Ю. Ахмедова, К. Аслана и др. исследователей. В целом следует отметить, что проблематика детского чтения активно исследуется в России еще со времен В.Белинского; к примеру, можно указать на произведения И. Феоктистова, Е.Н. Водовозовой, и др. ученых. Вместе с тем есть еще недостаточно исследованные стороны этой проблемы. К примеру, это вопросы детского чтения в творчестве Низами.

Целью статьи является анализ произведений азербайджанского поэта Низами с целью выявления его отношения к детскому чтению и воспитанию.

Основное содержание. Одним из важных качеств творчества Низами заключается в том, что, помимо проявления отношения к чтению и книгам, он также давал ценные сведения о книгах и библиотеках своего времени. Особое внимание уделял Низами вопросам обучения и воспитания молодого поколения, роли и задачам их в обществе. Согласно Низами, учиться, стремиться к знаниям, к науке является первостепенной задачей для каждого молодого человека. Поэт ценил науку как силу, способную на все. Реальную возможность служения обществу дает именно наука. Что же касается чтения, то здесь подчеркивается мысль о том, что именно через чтение можно достичь высот в своей жизни [2: 45].

В истории азербайджанской педагогической мысли своими позициями обладал известный азербайджанский исследователь - профессор Казанского университета Мирза Кязымбек. Он считал, что учебники для детей должны быть легкими для понимания, с интересными учебными материалами. В учебнике, составленном М. Кязымбеком, мы видим соблюдение всех требований относительно детского чтения. Одним из ведущих педагогических качеств его учебников является интересное содержание учебного материала. "Общая грамматика тюрко-татарского языка", "Учебник для краткого курса тюркско-османского языка" - в этих книгах приведены образцы фольклора, несколько анекдотов про Муллу Насреддина, отрывки из сказки "Тысяча и одна ночь", части произведений Физули, доступных для детей, и т.д. Тем самым видный педагог стремился пробудить интерес у юных читателей к восточной, в том числе азербайджанской культуре [3: 181].

Особое место в истории азербайджанской педагогической мысли занимаю идеи о роли и значении чтения в процессе обучения, приобщения к знаниям и науке в целом Аббаскулу Ага Бакиханова. А. Бакиханов считал науку основным средством достижения счастья. Он справедливо считал науку неотъемлемой частью развития человеческих способностей. Основной же путь достижения счастья - это постижение науки. Причем через чтение. Те же, кто этого не хотят делать, становятся невеждами.

Писатель советовал приучать к чтению детей с малых лет. Знаний никогда не бывает достаточно. Поэтому следует всегда работать над собой. Важным условием знаний, которые передаются детям, является их конкретность, точность и ясность. Имеется в виду не только ясность мысли в книгах, 
предназначенных для детского чтения, но и тех произведений, которые рекомендуют им читать и изучать.

Бакиханов особо подчеркивал, что детское чтение должно быть последовательным и систематическим. В своем учебнике под названием "Грамматика персидского языка" писатель в основу брал также воспитательный принцип. Автор придавал особое значение учебным материалам, отобранным для данного учебника с тем, чтобы подчеркнуть их воспитательное значение. При обучении детей важно учитывать их возрастные и психологические особенности, одновременно учитывать интересы каждого из них. В вышеуказанном учебнике все эти требования соблюдены.

Другим мыслителем, неоднократно подчеркивавшим роль чтения в жизни ребенка, является писатель Мирза Шафи Вазех. В своих произведениях он всерьез призывал воспитывать подрастающее поколение грамотным и обладающим высокими нравственными качествами. Вазех призывал в учебниках, предназначенных для детей, размещать материалы, способные пробудить в них симпатию к историческому прошлому народа, их правильно воспитывать.

Большое значение Вазех придавал учету возрастных особенностей детей, предлагая размещать в книгах для них юмористические произведения, прежде всего, маленькие рассказы. Очень важно правильно размещать произведения в книгах, издаваемых как учебники для детей, в учебникехрестоматии, составленном им самим, он подобрал такие произведения, которые могли бы сформировать у детей интерес и любовь к науке, просвещению, труду, желание быть честным, правдивым, становиться умнее, быть скромным. Важным считал Вазех приучать детей к изучению устного народного творчества. Следует помнить о возможностях воздействия на сознание и ум детей картинок в книгах, т.е. иллюстраций [3: 92].

Есть интересные мысли о значении чтения для детей также и у М. Ф. Ахундова. Чтение детей, как считал он, следует направить на изучение проблем природы и общества. В тот период, когда жил и творил Ахундов, в школьной системе обучения не очень-то следовали принципам учета возрастных способностей детей при подборе учебного материала. В итоге детям для чтения предлагали сложные для восприятия произведения "Гюлюстан" Ширази, "Бустан", "Лейли и Меджнун" Низами, "Тарихи-Надир" и проч. Сам Ахундов в перечень предметов для обучения включил в основном светские науки. Писатель так советовал тем, кто собрался писать произведения для детей и подростков: для вдохновления подрастающего поколения следует писать произведения выдающихся личностях, ученых, философах, врачах, поэтах и армейских командирах.

С целью закрепления знаний и навыков детей в процессе обучения Ахундов предлагал приводить показательные факты. В настоящее время в детских библиотеках приводится большое количество иллюстративного материала для детей. Ахундов клал в основу детского чтения принципы последовательности и системности.

Большую роль в становлении азербайджанской педагогической мысли сыграло творчество Сеида Азима Ширвани. Писатель рекомендовал тем, кто руководил детским чтением, выбирать детям книги в соответствии с их интересами. Здесь обязательно необходимо помнить об активности, сферах интересов детей. Следует еще с детских лет определиться в отношении интересов детей с тем, чтобы ориентировать их относительно какой-либо из наук. Кроме того, писатель высказал мнение о произведениях для детей, которые и по сегодняшний день весьма значимы. Он, в частности, выступал против того, чтобы обманывать детей придуманными рассказами и притчами. Он подчеркивал, что детские стихи должны их очаровывать, беспокоить, радовать, поднимать их дух. В произведениях, созданных им для детей, все указанные требования неуклонно соблюдаются.

Азербайджанская педагогическая мысль обогатилась трудами и идеями ряда мыслителей конца XIX начала XX столетия. Это в том числе и видный представитель педагогической мысли Азербайджана Фиридун Бек Кочарли. Он - выпускник и преподаватель знаменитой Горийской семинарии. Всю свою сознательную жизнь Ф. Кочарли служил своему народу. Он занялся рядом важных для общества проблем, среди которых следует назвать просвещение народа, в особенности, обучение и воспитание подрастающего поколения, правильная организация детского чтения и издание книг для детей. Основная деятельность этого выдающегося педагога состояла в просвещении детей, в их обучении. У него есть ряд ценных мыслей относительно содержания и идей детской литературы, чтения детей, и по сегодняшний день они значимы в школьном обучении и воспитании [3: 130].

Ведущее место в детском чтении, как считал Ф.Б. Кочарли, занимает удачно составленные в педагогическом отношении учебники для детей. Говоря о требованиях, предъявляемых к учебникам по литературе, Кочарли отмечал, что их следует писать на доступном для детского восприятия языке. В противном случае это приведет к ухудшению словарного запаса детей, они не станут знать от этого язык лучше. Язык учебников по языку и литературе должен содержать понятный и ясный учебный материал. Писатель подчеркивал, что дети не смогут понять материал, изложенный на трудном языке.

Следует избегать, подчеркивал Кочарли, употребления слов, чуждых ребенку, отрицательно сказывающихся на его речь и воспитание. Он требовал от авторов, чтобы те глубоко изучали народный 
язык, осторожно использовали чужеродные слова. Кочарли, обращаясь к конкретным фактам, учебникам, выделял здесь материалы с полезным содержанием, показывая наиболее трудно воспринимаемые детьми места, отмечая, что это делает данный материал трудным и даже бесполезным.

На книгопечатание Кочарли смотрел как на проявление высокой степени культуры, требуя печатать книги, удовлетворяющие развитому вкусу, в том виде, чтобы их было легко читать: "книги следует печатать на хорошей бумаге, ясным и красивым шрифтом". Требования Кочарли к учебникам по языку и литературе связаны с их содержанием. Содержание учебников он основательно различал от прочих книг. Он понимал, что учебник есть учебное пособие, созданное по соответствующей программе и охватывающее собой соответствующую сферу науки. Именно поэтому каждое правило, каждый литературный факт должен быть ясным и точным, анализ учебных материалов должен проходить на основе соответствующих дидактических принципов и методических приемов.

Что же касается материалов, которые включаются в детские учебники, то и здесь Кочарли выступает в роли умелого педагога. Приемлемым материалом он называл басни и детские стихи К. Б. Закира, С. А. Ширвани. Однако, приводя педагогические обоснования, он подчеркивал, что сразу после изучения алфавита эти произведения в состав произведений для чтения включать нельзя. Причина в словах персидского и арабского происхождения, которые есть в этих произведениях. Детям младшего школьного возраста трудно их воспринимать и понимать. Именно поэтому как вышеуказанных авторов, так и произведения классиков азербайджанской литературы XIX века можно давать изучать детям не первых и вторых классов, а третьих и четвертых.

Определяя место детской литературы в учебниках для детей по языку и литературе, Кочарли высказывал оригинальные суждения относительно педагогико-методических требований к данной литературе. Говоря о положительных качествах детской литературы, он подчеркивал, что для подростков, имеющих ограниченные представления о социальной жизни, это хорошая возможность познать мир. В связи с этим он ставил конкретные требования перед писателями, чье творчество было связано с детской литературой.

Известный педагог считал важным всестороннее развитие детской литературы, во имя будущего детей, как важной составной части общей художественной литературы. В качестве примера он обращался к творчеству А. Пушкина и Л. Толстого, выдающихся представителей русского народа, призывая своих современников учиться на их образцах детской литературы. Кочарли писал, что родной язык вдохновляет детей на учебу, и в их лице весь народ, пробуждая у них поэтические чувства. Мастер слова, пишущий для детей, должен писать просто, ясно и легко, чтобы суметь оказать воздействие на сознание детей [2: 46]. Кочарли высоко ценил роль чтения в нравственном воспитании детей, отмечая воспитательное значение и дидактический смысл художественных текстов.

В начале XX века важными вопросами и проблемами методической мысли занимался также Рашидбек Эфендиев. Более 50 лет он занимался педагогической деятельностью и имеет свою точку зрения относительно чтения детей, рассматривая как теоретические, так и практические вопросы. Р. Эфендиев высказал ценные мысли относительно детского чтения, его особенностей, роль чтения в изучении учебного материала, требований к учебникам, и т.д. Основные мысли Эфендиева относительно детского чтения высказаны в его произведениях "Детский сад" и "Басиратуль-этфал". Первая книга - это учебник для начальной школы.

Перед учебником стояли педагогические и методические требования относительно того, чтобы дети в Азербайджане как можно скорее выучили алфавит, научились быстро читать и писать. В этом учебнике помещены, в соответствии с возрастными и психологическими требованиями времени, небольшие рассказы, стихи, басни, пословицы и загадки. Высказывания Р. Эфендиева относительно художественных отрывков для этого учебника, принципов отбора художественного материала для него являются богатым поучительным материалом о детской литературе.

В учебнике автор ставит следующие педагогически-методические принципы перед произведениями, которые пишутся для детей:

1) детские произведения должны писаться на простом, понятном для детей языке;

2) детские стихи в художественном отношении должны быть яркими, по слогу игривыми и легкими;

3) они должны обладать эмоциональной силой и степенью художественного воздействия, доходить до сердец и нравственного мира детей;

4) детские произведения должны прививать детям добродетель, уважение к старшим, правдивость и честность [2: 171].

Передовые люди ХХ столетия ясно видели перспективы создания передовых школ нового типа, где работали бы люди-просветители и методисты. Именно такие школы они пропагандировали, считая их источником прогресса и передового развития. Они всячески стремились, взявшись рука-за-руку, создать сеть светских школ, отвечающих передовым требованиям современности, обучения и воспитания. Для этого было необходимо обеспечить их необходимыми методическими инструментариями. 
В эти требования входили обучение литературе с ранних лет. Обучать культуре чтения еще с ранних школьных лет, сохраняя при этом древнее и богатое наследие народа, на основе освоения детьми классического литературного наследия. Чтение детей должно соответствовать возрастным особенностям детей, их умениям и способностям. Чтобы правильно направлять их, следует составлять новые учебники по литературе, с новым содержанием. Одним из первых инициаторов этого дела был как раз Рашид Бек Эфендиев. Его учебник "Бесиратуль-этфал" стал совершенным учебником для школьников своего времени, он высоко ценился и в последующие времена.

В данном учебнике автор обратился к интересным литературным отрывкам. Помимо этого, здесь представлен богатый мир басен, в особенности русского баснописца И. А. Крылова. Использование басен здесь не случайно. Известно, что дети проявляют большой интерес к произведениям, где описываются звери, они с интересом читают отрывки с аллегорическим описанием жизни животных. Здесь, прежде всего, учитываются возраст, мировоззрение, психология детей [3: 161].

Автор учебника считал, что аллегорические произведения в школе пробуждают большой интерес к чтению, создают оживление в классе. Дети выдвигают суждения о героях произведения, о художественных образах, пытаются определить содержание аллегорического смысла произведения. Эфендиев, хорошо зная психологию детей, использовал жанр басни в учебнике по литературе.

Свои суждения о детском чтении, его правильной организации высказал известный азербайджанский политический деятель Нариман Нариманов. Будучи и писателем, Нариманов считал, что в литературе, рекомендуемой для чтения детям, нельзя использовать все. Здесь надо подходить избирательно. Произведение, рекомендуемое молодому поколению для чтения, должно воспитывать в детях высокую идейность, благородную мораль, формировать вкус и нравственные позиции. Свои мысли о детском чтении Н. Нариманов высказал в учебнике, составленном им, это "Краткий обзор тюркоазербайджанского языка" (1899). Для внеклассного чтения подбор материалов должен основываться на возрастных особенностях, язык должен быть простым, интересным по содержанию, сюда должны быть включены существенные отрывки, с точки зрения воспитания и обучения. Нариманов выступал против зубрежки, считал, что для хорошего усвоения материала нужно использовать вопросно-ответную форму работы.

Нариманов особо выделял произведения, где отражена жизненная правда, поскольку эти произведения воздействуют на мышление и формируют его. В этом отношении хорошим средством является устное народное творчество. Изучение истории народа, его обычаев, быта необходимо вести через его устное творчество. Именно поэтому писатель большое место уделил в своем учебнике именно народному творчеству. Здесь существенное место занимают сказки, поговорки, загадки и другие виды устного народного творчества.

Все произведения, подобранные здесь автором, прививают детям тягу к науке, к знаниям, высоким нравственным ценностям. Писатель подчеркивает, что то удовольствие, которое дает душе наука, ничто не может заменить. Тот, кто любит науку, идет от тьмы к свету. Человек может достичь счастья лишь обучаясь науке. Счастливый же человек через науку начнет помогать своему народу. Говоря о детском чтении, Нариманов высоко ценил принцип индивидуального подхода к каждому ученику, призывая учитывать разум ребенка, его способности и интерес к чтению. Мысли писателя о подготовке учащихся по литературе и языку и сегодня значимы, как для обучения детей, так и организации библиотечного дела.

Известно, что в Азербайджане дети получали начальное образование в моллахане. Здесь детей учили в основном без учета возраста и особенностей индивидуального развития. Они заучивали тексты, не особенно понимая их содержание. Именно поэтому уже в начале XX века демократически настроенные передовые просветители Азербайджана вели в печати открытую борьбу за передовые методы обучения и воспитания молодого поколения, в том числе и через чтение.

Здесь следует упомянуть имена Дж. Мамедкулизаде, О.Ф. Неманзаде, М. Махмудбекова, Ш. М. Ганизаде и других мыслителей, которые стремились способствовать прогрессивному развитию молодого поколения через правильное обучение, публикацию светских книг о науке и культуре, учет их возрастных особенностей. О.Ф. Неманзаде, рассуждая об общих особенностях книг для детей, подчеркивал, что книга должна быть изящно оформлена, написана простым языком, идейно прозрачна, а также оформлена иллюстрациями. Он писал, что маленькие читатели, которые еще не проявили должного интереса к чтению, могут именно через картинки заинтересоваться содержанием книги. Это помогает также хорошо усвоить содержание книги.

В своих произведениях О.Ф. Неманзаде резко критиковал подход властей к проблеме обучения, призывал соблюдать преемственность в обучении, учитывать уровень предыдущих знаний и возрастные особенности детей [3: 105]. Писатель подчеркивал, что подобно тому, как нельзя кормить мясом младенца, питающегося материнским молоком, также и нельзя детей, у которых еще не сформировалось умение рассуждать, заставлять изучать сложные и непонятные тексты. Обучение и формирование знаний следует начинать со сказок о животных и зверях, написанных легким слогом, с хорошими 
иллюстрациями, чтобы они понимали прочитанное и все это давало бы толчок их мыслительной деятельности. В целом автор стремился доказать, что правильная организация чтения школьников с учетом каждого возрастного этапа дает необходимый эффект.

Из сказанного можно сделать выводы о том, что организация детского чтения является важной проблемой для исследователей истории педагогической мысли Азербайджана, поскольку сам процесс чтения, его организация имеют большое значение в процессе обучения и воспитания подрастающего поколения. Анализ исторических фактов в развитии педагогической мысли Азербайджана показал, что здесь имеются богатые возможности по передаче опыта предыдущих поколений педагогов по обучению детей языку и литературе, по обучению всех предметов в школе в целом.

\section{СПИСОК ИСПОЛЬЗОВАННЫХ ИСТОЧНИКОВ И ЛИТЕРАТУРЫ}

1. Бабаева Т. Т. Проблема идентичности в литературном наследии Низами Гянджеви / Т. Т. Бабаева. - Баку : Нурлан, 2000. - 198 с.

2. Ахмедов Э. Ю. Информационно-библиотечное обеспечение детей и молодежи / Э. Ю. Ахмедов. - Баку : 2016. $-245 \mathrm{c}$.

3. Аслан Князь Роль художественной литературы в формировании личности / Князь Аслан. - Баку : 2008. $324 \mathrm{c}$.

4. Халафов А. А. Мудрые изречения о слове, книге, чтении, библиотеке и библиотекаре / А. А. Халафов. Баку : Мутарджим, 2014. - 187 с.

5. Джафаров Н. Избранные произведения / Н. Джафаров. - В пяти томах - Том 2. - Баку : Элм, 2007. - 336 с.

6. Ахмедов С. Низами и некоторые вопросы мировой педагогической идеи / С. Ахмедов. - "Учитель Азербайджана", 28 февраля 1992 года.

7. Алиев Р. Низами : Период, идентичность и подготовка / Низами Гянджеви. - Баку, 1993, № 1. - С. 7-17.

8. Гулиев С. М. Моральные вопросы в работе Низами Гянджеви / С. М. Гулиев. - Баку : АДПУ, 1994. -67 с.

9. Микаилов С. Н. О педагогических взглядах Низами Гянджеви / С. Н. Микаилов. - "Азербайджанская школа", 1984, № 9. - С. 47-52.

10. Белинский В. Г. О детской литературе: сборник / В. Г. Белинский, Н. Г. Чернышевский, Н. А. Добролюбов; [сост. В. В. Терновский и Н. И. Якушин; худ. Н. Воронова]. - 2-е изд., перераб. и доп. - Москва : Детская литература, 1983. - $430 \mathrm{c.}$

11. Водовозова Е. Н. Умственное и нравственное воспитание детей от первого проявления сознания до школьного возраста [Электронный ресурс] : [кн. для воспитателей] / Е. Н. Водовозова. - 6-е изд., испр. Санкт-Петербург : Типография М. М. Стасюлевича, 1907. - 364 с

12. Феоктистов И. К вопросу о детском чтении / Ив. Феоктистов. - 2-е изд., доп. - Санкт-Петербург : Типография П. П. Сойкина, [1903]. - 297 с.

\section{REFERENCES (TRASLATED \& TRANSLITERATED)}

1. Babaeva T. T. Problema identichnosti v literaturnom nasledii Nizami Giandzhevi [The Problem of Identity in the Literary Heritage of Nizami Ganiavi] / T. T. Babaeva. - Baku : Nurlan, 2000. - 198 s.

2. Akhmedov Je. Yu. Informatsionno-bibliotechnoe obespechenie detei i molodezhi [Information and Library Support of Children and Youth] / Je. Yu. Akhmedov. - Baku : 2016. - 245 s.

3. Aslan Kniaz Rol' hudozhestvennoi literatury $\mathrm{v}$ formirovanii lichnosti [The Role of Fiction in the Formation of Personality] / Kniaz Aslan. - Baku : 2008. - 324 s.

4. Halafov A. A. Mudryie izrecheniia o slove, knige, chtenii, biblioteke i bibliotekare [Wise Sayings about Word, Book, Reading, Library and Librarian] / A. A. Halafov. - Baku : Mutardzhim, 2014. - 187 s.

5. Dzhafarov N. Izbrannyie proizvedeniia [Selected Works] / N. Dzhafarov. - V piati tomah. - Tom 2. Baku : Jelm, 2007. $-336 \mathrm{~s}$

6. Akhmedov S. Nizami i nekotoryie voprosy mirovoi pedagogicheskoi idei [Nizami and Some Questions of the World Pedagogical Idea] / S. Akhmedov. - "Uchitel' Azerbaidzhana", 28 fevralia 1992 goda.

7. Aliev R. Nizami : Period, identichnost' i podgotovka [Nizami: Period, Identity and Training] / Nizami Giandzhevi. Baku, 1993, № 1. - S. 7-17.

8. Guliev S. M. Moral'nyie voprosy v rabote Nizami Giandzhevi [Moral Issues in the Work of Nizami Ganiavi]/ S. M. Guliev. - Baku : ADPU, 1994. - 67 s.

9. Mikailov S. N. O pedagogicheskikh vzgliadakh Nizami Giandzhevi [About Pedagogical Views of Nizami Ganiavi] / S. N. Mikailov. - "Azerbaidzhanskaia shkola", 1984, № 9. - S. 47-52.

10. Belinskii V. G. O detskoi literature [About Children's Literature] : [sbornik] / V. G. Belinskii, N. G. Chernyshevskii, N. A. Dobroliubov; [sost. V. V. Ternovskii i N. I. Jakushin; hud. N. Voronova]. - 2-e izd., pererab. i dop.. Moskva : Detskaia literatura, 1983. $-430 \mathrm{~s}$.

11. Vodovozova E. N. Umstvennoe i nravstvennoe vospitanie detei ot pervogo proiavleniia soznaniia do shkol'nogo vozrasta [Mental and Moral Education of Children from the First Manifestation of Consciousness to School Age] [Elektronnyi resurs] : [kn. dlia vospitatelei] / E. N. Vodovozova. - 6-e izd., ispr. - Sankt-Peterburg : Tipografiia M. M. Stasiulevicha, 1907. - $364 \mathrm{~s}$

12. Feoktistov I. K voprosu o detskom chtenii [On the Issue of Children's Reading] / I. Feoktistov. - 2-e izd., dop. Sankt-Peterburg : Tipografiia P. P. Soikina, [1903]. - 297 s. 
Ахмедов Е. Ю. Проблеми дитячого читання в історії азербайджанської педагогічної думки.

У даній статті описані проблеми дитячого читання в історії педагогічної думки Азербайджану. Зокрема, описано позииії Нізамі Гянджеві, Мірза Кязимбека, А. А. Бакіханова, Мірза Шафі Вазеха, Мірзи Фатали Ахундова, Сеїд Азима Ширвани, Фірідун Бека Кочарлі, Рашид Бека Ефендієва, Нарімана Наріманова, Омара Фаїк Неманзаде. Зроблено висновки про значущість науково-педагогічної та публіцистичної діяльності кожного із зазначених мислителів, наведені найбільш цінні, з точки зору досліджуваної тематики, думки про роль мови і літератури в навчанні дітей в школі. Показано значення зазначених ідей $і$ досліджень в сучасному педагогічному процесі.

Ключові слова: історія педагогічної думки Азербайджану, дитяче читання, шкільне навчання, мова $і$ література, дидактика і методика.

\section{Akhmedov E. Yu. Problems of Children's Reading in the History of Azerbaijani Pedagogical Thought.}

This article reveals the problems of children's reading in the history of Azerbaijani pedagogical thought. In particular, it showcases the views of Nizami Ganjavi, Mirza Kazymbek, A. A. Bakikhanov, Mirza Shafi Vazeh, Mirza Fatali Akhundov, Seid Azim Shirvani, Firidun Bey Kocharli, Rashid Bey Efendiyev, Nariman Narimanov, Omar Faig Nemanzade. The article presents conclusions about the importance of the scientific-pedagogical and journalistic activity of each of these thinkers and provides the most valuable thoughts on the role of language and literature in the education from the point of view of the researched topic. The article also demonstrates the value of these ideas and studies in the modern pedagogical process. Leading people of the twentieth century clearly saw the prospects for creating advanced schools of a new type, where enlightened people and methodologists would work. They propagated such schools, considering them a source of progress and advanced development. Organization of children's reading is an important problem for researchers of the history of Azerbaijan pedagogical thought, since the very process of reading, its organization are of great importance in the process of education and upbringing of the younger generation. An analysis of historical facts in the development of Azerbaijan pedagogical thought has shown that there are rich opportunities for transferring the experience of previous generations of teachers in teaching children language and literature, in teaching all subjects in the school as a whole.

Key words: history of Azerbaijani pedagogical thought, children's reading, school education, language and literature, didactics and methodology. 